\title{
PULP TISSUE REACTION TO DIRECT PULP CAPPING USING TWO DIFFERENT MATERIALS (A HISTOPATHOLOGICAL STUDY)
}

\author{
Marwa Abd ElHameed* and Zainab Diaa El Din Soliman**
}

\begin{abstract}
Background: Direct pulp capping (DPC) is a mandatory procedure to preserve pulp vitality. Resin modified pulp capping materials represent a category of materials that seal the pulp tissue and maintain its vitality in addition to the resin ability to copolymerize with resin composite restorations. Aim: The aim of this study was to evaluate the pulpal tissue reaction to resin containing calcium silicate base material (TheraCal LC Bisco Inc., Schaumburg, IL, USA) and resin containing light cured calcium hydroxide (Urbical LC Promedica Dental Material GmbH, Germany) when used as direct pulp capping materials. This was achieved through histopathological examination and statistical analysis of the histomorphometric collected data.
\end{abstract}

Materials and methods: 40 (six-week-old male albino rats) were used in this study. All rats undergone direct pulp capping procedure in their maxillary right first molars (20 rats per each capping material). The rats were further divided into two groups according to follow up periods of 7 and 14 days $(n=10)$. For the left maxillary $1^{\text {st }}$ molars, half of them $(n=5)$ acted as positive control group received pulp exposure procedure that was covered with sterile polytetrafluoroethylene (PTEF;Teflon tape) material. The other half on the left side acted as a negative control. At the end of each experimental period rats were sacrificed. The maxillae were dissected and processed to study the pulpal response to different DPC procedures - microscopically and statistically by the means of inflammatory cells count, calcific barrier area fraction and the mean area fraction of the remaining normal pulp tissue.

Results: At 7 days, UrbiCal treated teeth showed active formation of calcific barrier with varying levels of organization in each tooth. The formed barrier is almost resembling a fibrodentin. However, TheraCal treated teeth showed less active formation of calcific barrier. At day 14, Urbical capped pulps showed a more organized and well defined calcific barrier, almost resembling the surrounding normal dentin tissue. TheraCal treated group presented with a well-defined heterogeneous calcific barrier which was closely resemble a fibrodentin. According to our statistical results, the percentage of remaining normal pulp tissue and degree of inflammatory cell infiltration showed superior desirable measurements in Urbical treated groups.

Conclusion: Direct pulp capping prolonged the life span of pulpal tissue than if it was left untreated. Urbical pulp capping material provided the exposure site with a more organized calcific barriers, lesser inflammatory reaction with more preserved remaining pulpal tissue than TheraCal did.

KEY WORDS: Urbical, TheraCal, direct pulp capping, pulp exposure.

* Associate Professor, Oral biology, Faculty of dentistry, Ain shams University, Cairo, Egypt

** Lecturer in Department of Operative Dentistry, Faculty of Dentistry, Ain Shams University, Cairo, Egypt 


\section{INTRODUCTION}

Dental pulp (also known as tooth nerve) performs a wide range of functions including dentin formation and defense through the dentin-pulp complex, as well as providing sensory feedback ${ }^{(1)}$. Pulp is a loose connective tissue within the central pulp chamber ${ }^{(2)}$. It is comprised of a mixture of mesenchymal and para-axial mesenchymal cells, as well as cells from the cranial neural crest, which are present at the site of the dental papilla and tooth bud development ${ }^{(1)}$.

Fibroblasts, the predominating cell type in the pulp, are capable of synthesizing collagen and extracellular matrix. They are particularly involved in the process of healing in pulp tissue ${ }^{(1,3)}$.

In a study by Fitzgerlad et al. determined that in damaged tissue, fibroblasts may be stimulated to differentiate into replacement odontoblast cells ${ }^{(4)}$. Pulp cells and fibers as well as the blood vessels and nerves which enter and leave through the apical and other foramina are embedded within gel-like ground substance. Odontoblasts are abundant cell phenotype in the pulp. They have a critical function of supplying nutrients during dentin formation, hydration of mature dentin via dentinal tubules and modulating host defense mechanism through the pulp-dentin complex by triggering inflammatory and immune responses ${ }^{(5)}$.

Dental pulp connective tissue is mechanically protected from different stimuli by enamel, dentin and cementum ${ }^{(6)}$. Defense mechanisms involve inflammatory response, blocking the dentinal tubules and formation of secondary and tertiary dentin, as well as involvement of sensory fibers which give feedback on various stimuli. Despite this protection, the pulp may be injured, diseased or die ${ }^{(7)}$. Pulp irritation could be due to microorganisms or viruses, mechanical, chemical and thermal insults. Microbial irritants include bacterial species such as Streptococcus mutans and lactobacilli which produce toxins and penetrate into the pulp through dentinal tubules. The pulp under those tubules is then infiltrated locally and primarily by chronic inflammatory cells like macrophages, polymorphonuclear (PMN) plasma cells and lymphocytes and may form an area of necrosis which bacteria may colonize. Cytokines are secreted as part of an immune system response to stimuli and microorganisms (8). In the pulp not only odontoblast cells but also fibroblast cells have the potential to secrete the cytokines to initiate collagen formation and pulp repair $(9,10)$. Pulp may be inflamed chronically or undergo necrosis eventually, depending on the virulence of bacteria, their ability to stimulate release of inflammatory fluids with increase in intrapulpal pressure, the host defense, amount of circulation and lymph node drainage ${ }^{(11)}$. Dentin thickness will also influence the outcome ${ }^{(12)}$.

Pulp capping is a line of treatment that belongs to vital pulp therapy protocols undergone in cases of deep caries management with the aim of preserving pulp vitality ${ }^{(13)}$. Direct pulp capping encompasses the application of bioactive material in direct approximation to the pulp and immediate permanent restoration placement ${ }^{(14)}$. For asymptomatic exposed pulps due to trauma or caries, all treatment protocols are now shifting towards avoiding pulpectomy with strategies that involves either Direct pulp capping or pulpotomy ${ }^{(15)}$. The bioactive nature and good tissue response are major decisive factors for the success of pulp capping materials in addition to immediate placement of final restoration (16). High bond strength with the immediately placed composite restoration is one of the aims that should be fulfilled with pulp capping materials. ${ }^{(17)}$

A variety of direct pulp capping materials were introduced, all aiming to achieve a proper pulpal response and induction of pulp to produce mineralized tissue (18). Calcium hydroxide is considered the gold standard to pulp capping materials with the first reports of pulpal healing dated between 1934 and early 1940s. ${ }^{(19)}$. The material use was based on their ability to produce calcium and hydroxide ions which were assumed to lead to differentiation of undifferentiated pulp cells 
to odontoblasts and form hard tissue barrier at the site of exposure. ${ }^{(20,21)}$ However, calcium hydroxide showed drawbacks including tunnel like defects in the induced dentine bridges ${ }^{(22,23)}$. Long term clinical studies showed highly variable and unpredictable results mainly attributed to high solubility and dissolution of the material over time, in addition to the poor bond with composite restorations $(24,25)$. UrbiCal LC (Promedica GmbH, Germany) is calcium ion releasing bioactive pulp capping material that have the advantages of containing resin. It was developed to overcome the solubility, low compressive strength and poor bond strength to dental tissues and composite restorations ${ }^{(26)}$.

Calcium Silicates as pulp capping materials are characterized by high compatibility and ability to induce a good quality dentin bridge which lead to enhanced sealing ability and good pulpal response (25). TheraCal LC (Bisco, Schaumburg, IL, USA) was introduced in 2011 which is a light curable calcium silicate based material. The material was designed to be used as a direct and indirect pulp capping material with the advantage of fast setting due to its light curable resin, in addition to the ability to immediately place the final restoration and enhanced bonding between the two materials ${ }^{(27)}$. High bond strength values were reported between TheraCal and composite restorations compared with other calcium silicate-based materials $(28 ; 29)$ which was further increased with the use of etch and rinse adhesive as an intermediate layer ${ }^{(30 ; 31 ; 32)}$.

Due to the high bond strength value of Theracal and Urbical LC to resin composites and the limited in vivo studies on the pulpal reaction comparing them as direct pulp capping materials, this study was conducted to compare the pulpal reaction of two resin containing pulp capping materials in means of dentin bridge formation and inflammatory cell response.

\section{Methods}

40 six-week-old male albino rats (150 gm at the beginning of the experiment) were used in this study. Rats received drinking water ad libitum and were fed milk-wet bread during the whole experimental period ( $7 \& 14$ days). The whole experiment was performed under an institutionally approved protocol by Faculty of medicine Ain Shams Research Institute (MASRI)

Pulp capping procedure was performed to maxillary right first molars (20 rats per each capping material). The rats were further divided into two groups according to follow up periods of 7 and 14 days $(n=10)$. For the left side maxillary first molars, 5 rats received pulp exposure procedure that was covered with sterile polytetrafluoroethylene (PTEF;Teflon tap) material to act as a positive control. The other intact 5 molars acted as a negative control. At the end of each experimental period rats that represented each of the experimental groups in addition to the positive and negative control were sacrificed at the selected period ${ }^{(33)}$.

A combination of $(1 \mathrm{~mL} / \mathrm{kg})$ of Zoletil@ 50 (Virbac, Carros, France) and Rompun ${ }^{\circledR}$ (Bayer AG, Leverkusen, Germany) was used to achieve general anesthesia in rats. Each molar was disinfected with a sterile cotton pellet soaked in $2 \%$ chlorhexidine gluconate. A $0.8 \mathrm{~mm}$ sterile round low speed bur was used to perform round access cavities on middle third of the mesial surface. The bur was changed every two cavity preparations. The cavity depth was approximately half the diameter of the bur. Copious irrigation with sterile saline solution $(0.9 \% \mathrm{NaCl})$ was performed during the cavity preparation to prevent heat generation. Once the bur had penetrated the dentin, the dental pulp was exposed using a sterile sharp endodontic explorer (DG16, Dental USA Inc., Mc Henry, IL, USA) ${ }^{(33 ; 34) .}$

A sterile saline-soaked cotton pellet was used to control pulpal bleeding after the exposure. The cavity was dried using a sterile cotton pellet and the pulp capping material was applied immediately to the exposure site using an explorer. For both UrbiCal LC (Promedica Dental Material GmbH, Germany) and Theracal (Bisco, Schaumburg, IL, 
USA), a layer of the material was applied that did not exceed $1 \mathrm{~mm}$ and light cured for 20 seconds using Ellipar LED light curing unit (3M, ESPE) according to manufacturer instructions.

After pulp capping procedure was completed, excess material was removed from walls using sharp explorer and All Bond Universal (Bisco, Schaumburg, IL, USA) mild self-etching universal adhesive was scrubbed on cavity walls in two successive application each for 15 second. Excess solvent was evaporated for at least 10 seconds and until no visible movement of the material was present and the adhesive was light cured for 10 seconds according to manufacturer instructions. Restorative Z350 XT flowable composite (3M, ESPE) shade A2 was applied in no more than 2 $\mathrm{mm}$ thickness to restore and seal the access cavity. Excess material was extruded using celluloid strip through which the material was light cured for 20 seconds. Any excess composite material was removed using a yellow coded low speed finishing stone under copious water irrigation. Rats were left for the experimental periods then teeth were processed for histological assessment

\section{Histological Assessment}

All Maxillae with enclosed molars were dissected, fixed in $10 \%$ buffered formalin solution for 2 weeks and then demineralized in $5 \%$ nitric acid. Once complete demineralization was confirmed (within 48-72 hrs) using sharp dental probe, specimens were embedded in paraffin blocks. Three to 7 microns thick serial sections were cut in the mesio-distal plane and stained with hematoxylin and eosin (H\&E) ${ }^{(35)}$. Histological analyses were performed on the H\&E-stained specimens using an optical microscope connected to a high-resolution video camera (Olympus Optical Co., LTD, model BX40F4. JAPAN).

All sections of the examined teeth were assessed histomorphometrically in Oral Pathology Department, Faculty of Dentistry. Our measurement criteria were (number of the inflammatory cells, area percentage occupied by calcified deposits and the area fraction of the remaining pulpal tissue in +ve control group \& experimental groups). The average of the 5 reading values for each specimen at (400 $\mathrm{x})$ was calculated using image $\mathrm{J}$ analysis software at Oral Pathology Unit, faculty of dentistry, Ain Shams University. The mean values were calculated and the results were statistically analyzed, data were presented as mean and standard deviation values. One way ANOVA \& Paired t-test were used to compare between the groups. Statistical analysis was performed with IBM (IBM Corporation, NY, USA) SPSS (SPSS, Inc., an IBM Company)statistics version 18 for windows. The normal distribution of all continuous variables was verified using the Kolmogorov Smirnov test. All P-values are two-sided. $\mathrm{P}$-values were considered significant at $\mathrm{P}<0.05$.

\section{Histological Results}

\section{7 days following direct pulp capping}

Histological examination of pulp tissues of the negative control intact teeth exhibited a welldefined odontoblast layer, a zone of Weil (cell free zone), a cell-rich zone and central pulp core with normal architecture. Inflammatory cells were minimally observed. (Figure 1A)

In UrbiCal treated teeth, active formation of calcific barrier with varying levels of organization was noticed after 7 days in the majority of teeth. The formed barrier almost resembling a fibrodentin. The surrounding pulpal tissue showed hemorrhagic zones with obvious inflammatory cells infiltration. No definite layer of odontoblasts or zone of Weil could be identified in areas adjacent to the newly formed dentin (Figures 1B). However, TheraCal treated teeth showed less active formation of calcific barrier at $\mathbf{7}$ days interval. The pulp tissue in contact with the material showed less vascular reaction than those of the UrbiCal group, but showed atrophy and disorganization of the odontoblast layer. Moreover, inflammatory cells infiltration was clearly observed (Figure 1C). 


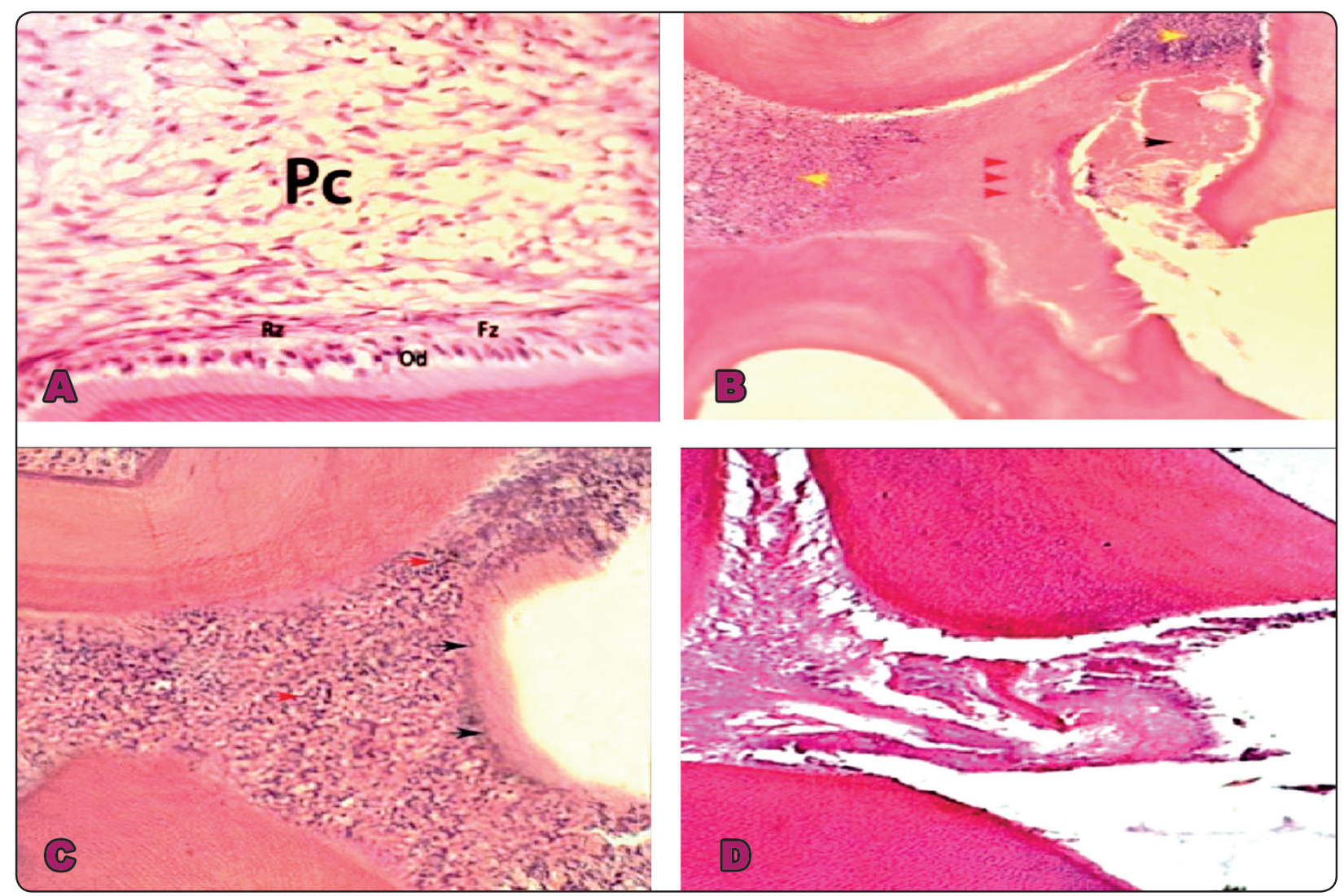

Fig. (1): A, pulp tissue from negative control group showing almost normal pulp architecture, with easily distinguishable odontoblasic layer $(\mathrm{Od})$, cell free zone $(\mathrm{Fz})$, cell rich zone $(\mathrm{Rz})$ and central pulp core $(\mathrm{Pc})$. B, UrbiCal treated pulps after 7 days showed formation of calcific barrier (red arrowheads). The formed barrier seemingly dentin-like structure. The surrounding pulpal tissue showed hemorrhagic zones (black arrowheads) with an obvious inflammatory cell infiltration (yellow arrow heads). No definite layer of odontoblasts or zone of Weil could be identified in areas adjacent to the newly formed tissue. C, TheraCal treated teeth showed less active formation of calcific barrier at 7 days. The pulp tissue in contact with the material (black arrowheads). Moreover, inflammatory cells infiltration was clearly observed (red arrowheads). D, The pulp tissue architecture in the positive control group (Teflon tape capped pulp) at 7 days, showed severe disruption and disorganization with almost complete tissue destruction in most regions. ( H \& E, X400)

The pulp tissue architecture in the +ve control group (Teflon tape capped pulp) at $\mathbf{7}$ days, showed severe disruption and disorganization with almost complete tissue destruction in most regions (Figure 1D).

\section{4 days following direct pulp capping}

No significant differences were found regarding the negative control groups between 7- \& 14-days intervals.

UrbiCal capped pulps at $\mathbf{1 4}$ days showed a more organized and well-defined calcific barrier, almost resembling the surrounding normal dentin tissue. The pulp also exhibited less intense inflammatory and vascular reaction with restored odontoblastic layer in most regions of the pulp except of local disruption of the odontoblastic layer was observed at the exposure site in all samples. Sporadic randomly distributed intra-pulpal dentin islands were also noticed in some treated molars. (fig. 2 (A))

TheraCal treated group at $\mathbf{1 4}$ days showed a well-defined heterogeneous calcific barrier which closely resembled fibrodentin. The subjacent pulpal tissue still showed obvious inflammatory cells 


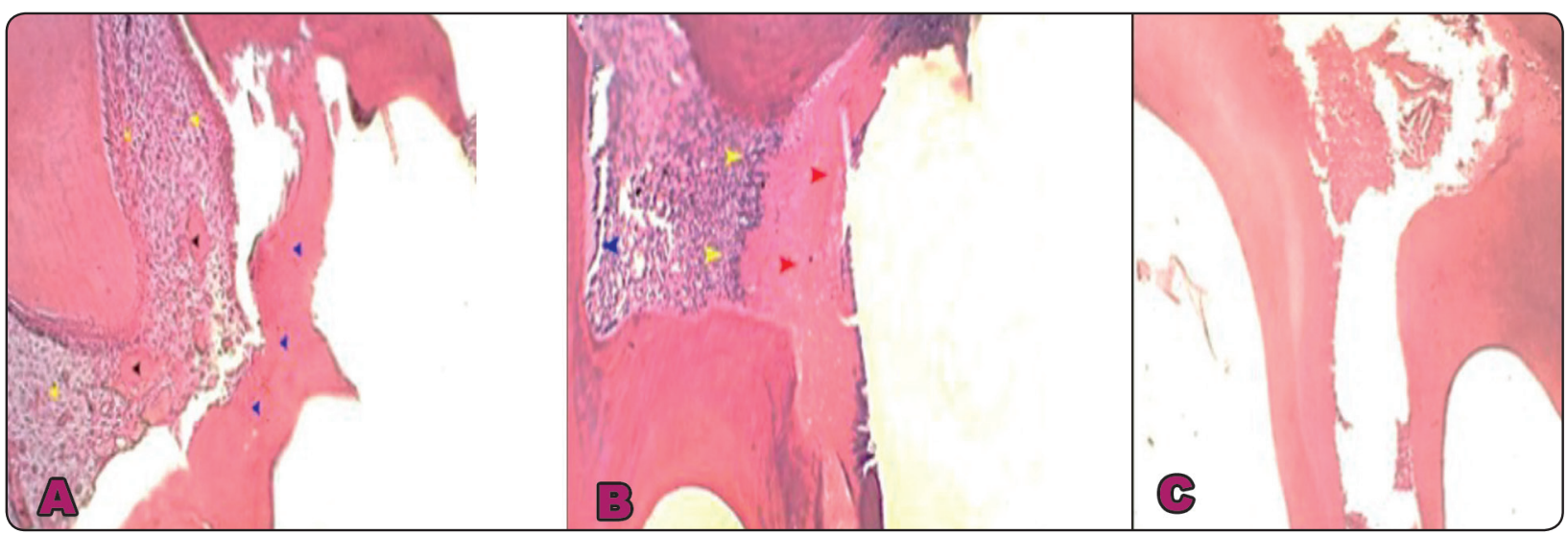

Fig. (2): A, Urbical LC capped pulps at 14 days showed a more organized and well-defined calcific barrier (blue arrowheads), The pulp also exhibited less intense inflammatory infiltration with restored odontoblastic layer and central pulp in most regions (yellow arrowheads). Sporadic randomly distributed intra-pulpal dentin islands were also noticed in some specimens (black arrowheads). B, TheraCal treated group at 14 days showed a well-defined heterogeneous calcific barrier which was seemingly dentin like structure (red arrowheads). The subjacent pulpal tissue showed obvious inflammatory cells infiltration with disruption of the odontoblastic layer (yellow arrowheads). Regions far from the exposure site showed restored odontoblastic layer to some extent (blue arrowheads). C, Teflon tape treated cavities at 14 days showed almost complete destruction and tissue shrinkage in wide pulp regions. ( $\mathrm{H} \& \mathrm{E}, \mathrm{X} 400$ )

infiltration with disruption of the odontoblastic layer and low vascular reaction. However, the regions far from the cavity showed restored odontoblastic layer to some degree. (fig. 2 (B))

Teflon tape treated pulps at $\mathbf{1 4}$ days some specimens showed almost complete degeneration in wide areas of the pulp, while others showed shrunken and almost necrosed tissue. (fig. 2 (C))

\section{Statistical Results:}

\section{1-Inflammatory cell count:}

The highest mean value of the inflammatory cells was recorded in TheraCal groups followed by Urbical group and the least was for the -ve control group. The positive control group was excluded due to the massive tissue destruction occurred.

There was significant difference between both materials and between each one and the -ve control specimens at 7 days. However, the results showed no significant difference between the UrbiCal group and the -ve control one at 14 days. (fig. 3)

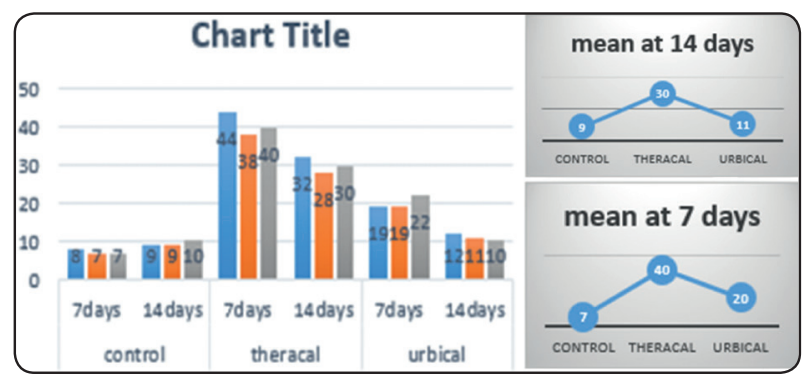

Fig. (3): Mean values of inflammatory cell count among -ve control, UrbiCal and TheraCal treated groups

\section{2-Percentage of remaining normal pulp tissue:}

There was significant difference between the $+v e$ control groups at $7 \& 14$ days. The least remaining tissue was recorded at 14 days sacrificed groups. (Fig. 4)

\section{3-Calcified barrier:}

The highest mean values of the formed intrapulpal calcific deposits were recorded in Urbical groups at day 14 followed by Theracal group at day 14 . The least records scored for the -ve control group followed by TheraCal treated teeth at day 7 . The positive control group was excluded due to the massive tissue destruction occurred. 


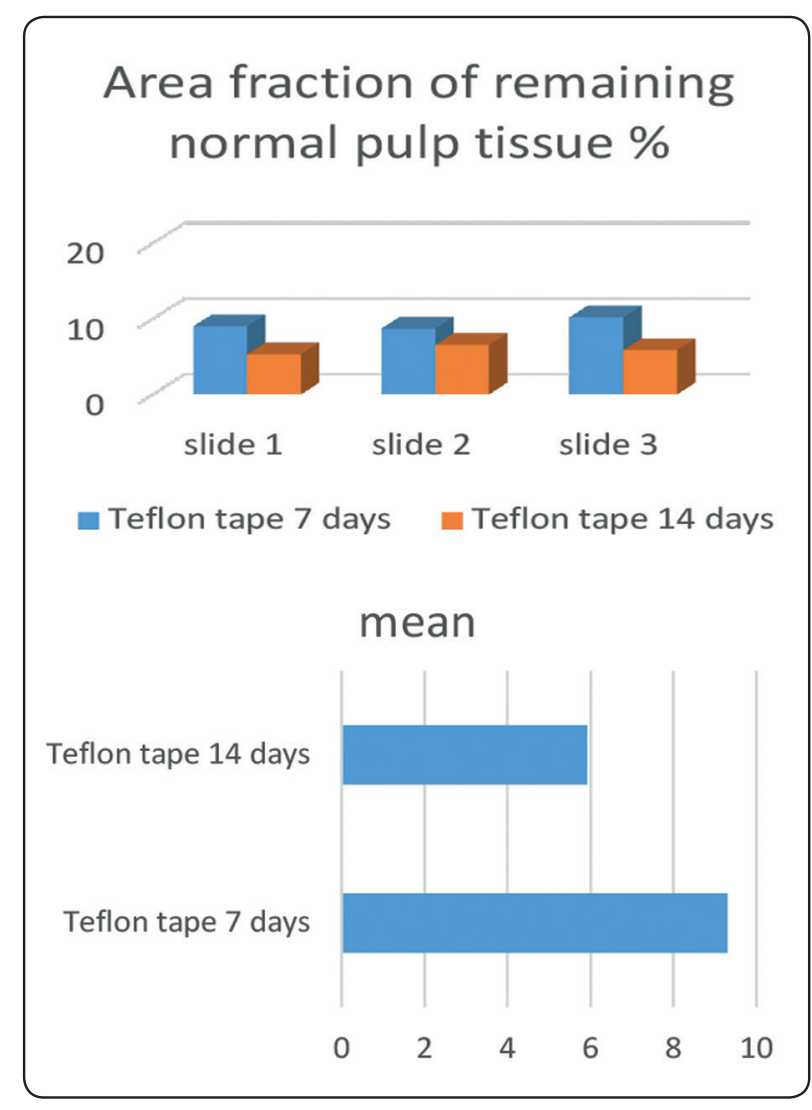

Fig. (4): Mean values of area percentage occupied by pulpal tissue.

There was significant difference between both materials and between each one and the -ve control specimens at $7 \& 14$ days. (Fig. 5)

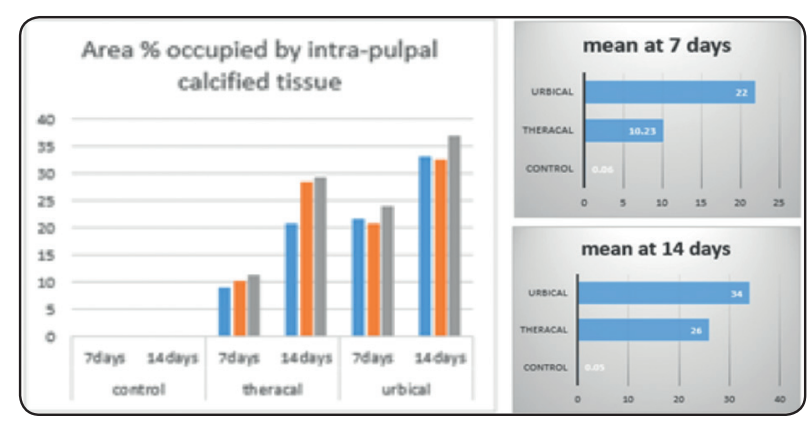

Fig. (5): Mean values of area percentage occupied by intrapulpal calcified tissue.

\section{DISCUSSION}

Direct pulp capping is a procedure aimed at preserving the vitality of mechanically exposed pulp from a restorative procedure or dental trauma. The result of pulp exposure if not properly managed, tissue inflammation and necrosis will occur which lead to endodontic treatment. The exposed pulp must be covered with a biocompatible capping material, followed by a coronal seal to protect the pulp from additional injury. Thereby, the material should be biocompatible and neither toxic nor irritating to avoid inflammatory, allergic or carcinogenic tissue response. ${ }^{(36)(37)}$

According to ISO 7405:2008 for dentistry, animal studies are recommended to assess the efficacy and biocompatibility of new pulp-capping materials or therapeutic medicaments ${ }^{(38)}$. Rat molars are usually selected as an experimental animal model due to their similarities to human molars in terms of anatomical, histological and biological features ${ }^{(39)}$.

Rat molar pulp is expected to show a self-repair capacity, with auto-deposition of osteodentin-like matrix observed in the coronal pulp after pulp exposure, even in the absence of pulp capping material. To distinguish the biological effect of capping materials from the exceptional reparative capacity, a positive control was carried out using the same experimental protocol. This was achieved by replacing the capping material with PTFE tape, a chemically inert material ${ }^{(40)}$.

The preference for mesial exposure in our study was due to the ease of access in cavity preparations related to the space available between the rat incisors and the first molars. In addition to this, the mesial site is a non-stress bearing area ${ }^{(41)}$.

At $7 \& 14$ days, pulp capping with PTFE tape led to a persistent inflammatory response and incomplete dentin bridge formation at the exposure area and tissue degeneration, similar to results of previous studies ${ }^{(42 ; 43)}$. This was speculated to be a result of the inability of PTFE tape to regenerate and stimulate the differentiation of pulpal cells. PTFE 
tape was also ineffective in the promotion of pulpal healing or stimulation of a consistent dentin bridge formation at the exposure sites ${ }^{(43)}$.

Many in vivo studies have demonstrated more favorable healing of the pulp-dentin complex after direct pulp capping with MTA based materials than with the conventional pulp capping material; calcium hydroxide. MTA stimulated fewer inflammatory reactions and was found to induce a thicker and more uniform mineralized tissue bridge ${ }^{(44 ; 4)}$. In our study, we observed microscopically more inflammatory cells and less organized dentin bridge with TheraCal. This may be attributed to that this material as one of calcium silicate hybrid material contains $43 \%$ resins. It is presented as a ready-to-use material in a syringe and sets by photopolymerization (20 sec/increment) in water free environment ${ }^{(46)}$. The byproduct formation from calcium silicate hybrid materials upon setting is different from those observed in resin free calcium silicate materials. However, these products represent a risk to the pulp vitality due to the resin components and their potential toxicity ${ }^{(47)}$.

Most capping materials lead to calcium hydroxide formation, and leaching of hydroxyl ions and calcium ions as demonstrated for MTA and Biodentin ${ }^{(48 ; 49)}$.The released hydroxyl ions upon hydration will increase the $\mathrm{pH}$ in the underlying tissue leading to a thin necrotic layer between the remaining vital tissue and the pulp capping agent $(50 ; 21)$.This might account for our observations, regarding the presence of a disorganized and distorted pulpal layer subjacent to the exposed capped sites. Moreover, Trongkij et al. also stated that the formation of a necrotic zone which might protects the underlying vital pulp cells from the material alkaline $\mathrm{pH}^{(33)}$. Furtherly, it enhances healing and regeneration of pulp cells ${ }^{(51)}$. The alkaline $\mathrm{pH}$ ensures antimicrobial activity ${ }^{(52)}$. The subsequent calcification of this necrotic layer followed by 3ry dentin formation from stimulated pulp cells to form a protective calcific barrier. $\mathrm{Ca}++$ contribute in this as they stimulate DPSC ${ }^{(53)}$.
Interestingly, TheraCal has been shown to release less calcium ions and no calcium hydroxide formation was seen when studied by X-ray diffraction analysis. Absence of calcium hydroxide in the set material may be related to its resin content which modifies the hydration reaction of the material, making it different than other calcium silicate-based cements in the kinetics of calcium ion release. The resultant concentration of released calcium ion is less compared to other calcium silicate-based cements. This may be due to incomplete hydration with limited moisture diffusion owing to the resin content ${ }^{(53)}$. Still, the material is able to release calcium ion in concentrations that stimulate the reparative activity of pulp and odontoblasts which is reflected as tooth remineralization capacity ${ }^{(53 ; 54)}$.

Absence of calcific barrier at 7 days and minimal barrier formation at 14 days in the current experiment may be related to the low biocompatibility of the Theracal which causes a higher degree of inflammation reflected by the significantly higher level of inflammatory cells expression in all experimental periods. These results were in accordance with other studies and could be attributed to the resin content of the material which is Bisphenol A-glycidyl methacrylate which is identified with its glutathione synthesis inhibitor, an intracellular antioxidant, and also interferes with some fundamental proteins needed for the process of pulp repair such as collagen type one formation. Also, Bisphenol A-glycidyl methacrylate had a cytopathic effect on some cells ${ }^{(55-58)}$.

Other studies also documented that TheraCal produced the least favorable pulpal responses compared to both ProRoot MTA and RetroMTA in addition to lower quality calcific barrier formation, extensive inflammation and less favorable odontoblastic layer formation ${ }^{(25)}$. Theracal was also reported to be toxic to pulp fibroblasts and has a higher inflammatory effect and a lower bioactive potential than Biodentin ${ }^{(44)}$. Those findings were attributed to the presence of acrylic monomer BisGMA in the material ${ }^{(59)}$. Presence of resin in the pulp 
capping agent which may remain unpolymerized is often associated with adverse pulpal reactions that lead to pulp toxicity and inflammation. Those findings coincide with another study which reported that the reparative capacity of TheraCal LC is inferior to Biodentin ${ }^{(60)}$.

On the other hand, calcium hydroxide products are considered the gold standard for pulp capping materials with a mode of action that decrease the plasma outflow which results in a calcific response in the pulpal tissue ${ }^{(61)}$. Three types of calcium hydroxide materials were presented in the market; the one paste non-setting calcium hydroxide which had the disadvantages of lack of setting and poor mechanical proprieties in addition to dissolution with calcific barrier characterized by tunnel defects $^{(24)}$. The two-paste calcium hydroxide system which had a setting time between 2-6 minutes. Still, the materials showed solubility and dissolution over time ${ }^{(62)}$. Among the three formulations, the highest cytotoxicity levels were reported with the two-paste system and lowest rates of cell vitality which was attributed to the added components in the system such as disalicylate, accelerator and plasticizer $^{(63)}$. Upon comparing the cell vitality results of the two paste systems (Dycal) with resin composite, the two paste-system showed significantly higher cytotoxicity to human pulp cells ${ }^{(64)}$.

Light curable calcium hydroxide has the advantage of being light polymerized producing immediate superior physical properties with the ability of immediate restoration placement and bonding system application with or without acid etching. Furthermore, the light curable materials are characterized by low solubility and dissolution over time ${ }^{(65)}$. Still, this category of materials had the disadvantage of all resin containing materials which is incomplete resin polymerization and resin leaching from set material which results in toxicity to pulp cells ${ }^{(66)}$.

Upon comparing the cytotoxicity of different calcium hydroxide formulations, it was found that resin containing calcium hydroxide (Calcimol LC) had higher cytotoxicity than self-setting one paste system (Calcicur) but exhibited similar or lower cytotoxicity than two paste system (Dycal). Invitro studies showed that light curable resin containing calcium hydroxide formulas showed same degree of cytotoxicity expressed by other resin free calcium hydroxide when the former is properly cured ${ }^{(67 ; 68)}$. It is worth mentioning that resin-based materials exhibit mostly $70 \%$ degree of conversion, the remaining $30 \%$ represents the available groups ready for polymerization, while only $9 \%$ represents the free monomer that can leach out of the matrix. Still, most of the free monomer is present inside the matrix of the material and would not leach out it ${ }^{(65)}$.

Though Theracal LC has lower solubility that other silicate-based cements and Calcium hydroxides, but when Theracal is compared to them, it is characterized by low biocompatibility with odontoblast like cells compared ${ }^{(69)}$.

\section{CONCLUSIONS}

Direct pulp capping prolonged the life span of pulpal tissue than if it was left untreated. Urbical pulp capping material provided the exposure site with a more organized calcific barriers, lesser inflammatory reaction with more preserved remaining pulpal tissue than TheraCal did.

\section{REFERENCES}

1. Cells and Extracelluar Matrices of Dentin and Pulp : A Biological Basis For Repair and Tissue Engineering. A., Goldberg J. M. and Smith. (1), 2004 Jan 1, Crit Rev Oral Biol Med, Vol. 15, pp. 13-27.

2. Stem cells and the dental pulp: potential roles in dentine regeneration and repair. Sloan A. J. and Smith A.J. (2), 2007 Mar, Oral Dis., Vol. 13, pp. 151-7.

3. Walton, Richard E and Torabinejad, Mahmoud. Principles and practice of endodontics. s.l.: Philadelphia : W.B. Saunders, 1996. 2nd ed.

4. Autoradiographic analysis of odontoblast replacement following pulp exposure in primate teeth. Fitzgerald M, Chiego DJ, Heys DR. 1990, Archs. oral Biol., Vol. 9, pp. 707-15. 
5. D.H. Pashley: Dynamics of the Pulpo-Dentin Complex. Pashley, D.H. 2, 1996, Intern \& Amr Associt Dent Res, Vol. 7.

6. Pathogenic mechanisms in pulpal disease. Bergenholtz, G. 2, 1990 Feb, J Endodont, Vols. Volume 16, Issue 2, February 1990, Pages 98-101, pp. 98-101.

7. Pathogenesis of pulpitis resulting from dental caries. Trowbridge, HO. 1981, J Endodont, Vol. 7, pp. 52-60.

8. Proinflammatory cytokine profiles in pulp fibroblasts stimulated with lipopolysaccharide and methyl mercaptan. COIL, J., TAM, E. \& WATERFIELD, J. D. 20, 2004, J Endodont, Vol. 30 ,pp. 88-91.

9. Interleukin-1beta activity and collagen synthesis in human dental pulp fibroblasts. Barkhordar R. A., Ghani Q. P., Russell T. R. \& Hussani M.Z. 3, 2002, J Endodont, Vol. 28, pp. 157-9.

10. Differential regulation of immune responses by odontoblasts. Veerayutthwilai O., Byers M. R., Pham T. T., Darveau R. P. \& Dale , B. A. 1, 2007, Oral Microbiol Immunol, Vol. 22, pp. 5-13.

11. The future role of a molecular approach to pulp-dentinal regeneration. . Tziafas, D. 3, 2003, J Caries Rest., Vol. 38, pp. 314-20.

12. Clinical signs and symptoms in pulp disease. . Dummer P. M., Hicks R. \& Huws D. 1, 1980, Int Endod J, Vol. 13, pp. 27-35.

13. European Society of Endodontology position statement: Management of deep caries and the exposed pulp. H.F., Duncan, et al. 2019, nt. Endod. J., Vol. 52, pp. 923-34.

14. Bioceramics. . L.L., Hench. 2005, J. Am. Ceram. Soc.., Vol. 81, pp. 1705-28.

15. Management of deep caries and the exposed pulp. Bjørndal, L., et al. 2019, Int. Endodont. J., Vol. 52, pp. 949-73 .

16. Vital pulp therapy of mature permanent teeth with irreversible pulpitis from the perspective of pulp biology. L.M., Lin, et al. 2019, Aust. Endod. J.

17. Shear Bond Strength of a Resin Composite to Six Pulp Capping Materials Used in Primary Teeth. Alhowaish L., Salama F. , Al-Harbi M. , Abumoatt M. 4, 2020, J Clin Pediatr Dent, Vol. 44, pp. 234-9.

18. Biocompatible and bioactive replacement for dentine: is this a reality? The properties and uses of a novel calciumbased cement. Bachoo K., Seymour D., and Brunton P.A. 2, 2013, Brit Dent J., Vol. 214.
19. Calcium hydroxide pastes: Classification and clinical indications. W.P., Fava L.R.G. and Saunders. 1999, Int. Endod. J. , Vol. 32, pp. 257-82.

20. Properties and applications of calcium hydroxide in endodontics and dental traumatology . H., Mohammadi Z. and Dummer P. M. 8, 2011, Inter Endo J, Vol. 44, pp. 697-730.

21. Human tooth culture: a study model for reparative dentinogenesis and direct pulp capping materials biocompatibility. Tecl' es O., Laurent P., Aubut V., and About L. 1, J. Biomed. Mat. Resch B : App. Biomat : s.n., 2008, Vol. 8, pp. 180-7.

22. Tunnel defects in dentin bridges: Their formation following direct pulp capping. C.F., Cox, et al. 1996, Oper. Dent. , Vol. 21,pp. 4-11.

23. Keys to Clinical Success with Pulp Capping: A Review of the Literature. T.J., Hilton. 2009, Oper. Dent., Vol. 34, pp. 615-25.

24. Current status of direct pulp-capping materials for permanent teeth. T., Komabayashi, Q., Zhu and Y., Eberhart R. and Imai. 2016, J Dent. Mater. , Vol. 35, pp. 1-12.

25. Bio-Inductive Materials in Direct and Indirect Pulp Capping-A Review Article. Kunert M., and LukomskaSzymanska M. 2020, J Materials, Vol. 13.

26. Calcium hydroxide liners: A literature review. NZ., Arandi. 2017, Clin Cosmet Investig Dent J., Vol. 9, pp. 67-72.

27. 27. Calcium silicate and calcium hydroxide materials for pulp capping: Biointeractivity, porosity, solubility and bioactivity of current formulations. M.G., Gandolfi, et al. 2015, J. Appl. Biomater. Funct. Mater. , Vol. 13, pp. 41-60.

28. Bonding over Dentin Replacement Materials. . Meraji, N. and Camilleri, J. 2017, J. Endodont, Vol. 43, pp. 1343-9.

29. Shear bond strength evaluation of resin composite bonded to three different liners: TheraCal LC, Biodentine, and resin-modified glass ionomer cement using universal adhesive: An in vitro study. J. Conserv. D. V., Deepa, et al. 2016, J. Conserv. Dent., Vol. 19, p. 166.

30. Bond strength of different restorative materials to lightcurable mineral trioxide aggregate. K., Cantekin. 2015, J. Clin. Pediatr. Dent. , Vol. 39, pp. 143-8.

31. Evaluation of the bond strength of different adhesive agents to a resin-modified calcium silicate material (TheraCal LC). Scanning. Karadas, M., et al. 2016, Scanning, Vol. 38, pp. 403-11. 
32. A confocal laser scanning microscopic study evaluating the sealing ability of mineral trioxide aggregate, Biodentine and new pulp capping agent-TheraCal. S., Makkar, H., Kaur and R., Aggarwal A. and Vashish. 2015, Dent. J. Adv. Stud., Vol. 3, pp. 20-5.

33. Effects of the exposure site on histological pulpal responses after direct capping with 2 calcium-silicate based cements in a rat model. Trongkij P., Sutimuntanakul S., Lapthanasupkul P., Chaimanakarn C., Wong R., Banomyong D. 4, 2018 Nov, Restor Dent Endod J., Vol. 43 , p. e36.

34. Controlled release of lovastatin from poly(lactic-coglycolic acid) nanoparticles for direct pulp capping in rat teeth. Lin HP, Tu HP., Hsieh YP, and Lee BSh. 2017, Intern J Nanomed, Vol. 12 , pp. 5473-85.

35. Bone sialoprotein-induced reparative dentinogenesis in the pulp of rat's molar. Decup F., Six N., Palmier B., Buch D., Lasfargues JJ., Salih E., et al. 2000, Clin Oral Investig J, Vol. 4,pp. 110-9.j

36. Carcinogenicity and metallic implants. Vahey J. W., Simonian P.T., and Conrad III E. U., 1995, Amr J Orthoped, Vol. 4, pp. 319-24.

37. Comparative Study of Pulpal Responses to Pulpotomy with ProRoot MTA, RetroMTA, and TheraCal in Dogs' Teeth. Lee, H., et al. 2015, J. Endod. , Vol. 41, pp. 1317-24.

38. Evaluation of biocompatibility of medical devices used in dentistry. Part 6: test procedures specific to dental materials. 2nd ed. New York (NY):. Dentistry, ISO. ISO 7405: 2008. 2008, International Organization for Standardization, pp. 19-27.

39. Rat molar teeth as a study model for direct pulp capping research in dentistry. T., Dammaschke. 2010, Lab Anim , Vol. 44, pp. 1-6.

40. Effects of mineral trioxide aggregate on human dental pulp cells after pulp-capping procedures. Paranjpe A., Zhang H. and Johnson JD. 2010, J Endod, Vol. 36, pp. 1042-7 .

41. Response of inflamed pulps of rat molars after capping with pulp-capping material containing fluocinolone acetonide. Louwakul P., Lertchirakarn V. 2015, J Endod , Vol. 41, pp. 508-12.

42. Healing of primate dental pulps capped with Teflon. Heys DR, Fitzgerald M, Heys RJ, Chiego DJ Jr. 1990, Oral Surg Oral Med Oral Pathol, Vol. 69 , pp. 227-37.

43. Hard tissue barrier formation in pulpotomized monkey teeth capped with cyanoacrylate or calcium hydroxide for
10 and 60 minutes. Cvek M, Granath L, Cleaton-Jones P, Austin J. 1987, J Dent Res, Vol. 66 , pp. 1166-74.

44. Light-cured tricalcium silicate toxicity to the dental pulp. Jeanneau C, Laurent P, Rombouts C, Giraud T and About I. 2017, J Endod, Vol. 43, pp. 2074-80.

45. Pulp progenitor cell recruitment is selectively guided by aC5a gradient. Chmilewsky F, Jeanneau C, Laurent P, Kirschfink M and About I. 2013, J Dent Res, Vol. 92, pp. 532-9.

46. Recent Trends in Tricalcium Silicates for Vital PulpTherapy. I, About. 2018, Curr Oral Health Rep , Vol. 5, pp. 178-85.

47. Pulp capping materials modulate the balance between inflammation and regeneration. Giraud T., Jeanneau CH., Rombouts CH., Bakhtiar H., Laurent P., et al.. 1, 2019, J Dent Mater, Vol. 35, pp. 24-35.

48. Investigation of thehydration and bioactivity of radiopacified tricalcium silicatecement, Biodentine and MTAAngelus. Camilleri J, Sorrentino F, Damidot D. 2013, J Dent Mater, Vol. 29, pp. 580-93.

49. Ion release and mechanical properties of calciumsilicate and calcium hydroxide materials used for pulpcapping. Natale LC., Rodrigues MC., Xavier TA., Simões A., de Souza DN. and Braga RR. 2015, Int Endod J, Vol. 48, pp. 89-94.

50. Mineraltrioxide aggregate (MTA) and calcium hydroxide aspulp-capping agents in human teeth: a preliminary report. Aeinehchi M., Eslami B., Ghanbariha M, Saffar AS. 2003, Int Endod J , Vol. 36, pp. 225-35.

51. Effects of calcium hydroxide-containingpulp-capping agents on pulp cell migration, proliferation, and differentiation. U, Schröder. 1985, J Dent Res, Vol. 64, pp. 541-8.

52. Physicaland chemical properties of a new root-end filling material. Torabinejad M., Hong CU., McDonald F. and Pitt Ford TR. 1995, J Endod, Vol. 21, pp. 349-53.

53. Hydration of biodentine, theracal LC, and a prototype tricalcium silicate-based dentin replacement material after pulp capping in entire tooth cultures. Camilleri J, Laurent P, About I. 2014, J Endod, Vol. 40, pp. 1846-54.

54. Chemical-physical properties of TheraCal, a novel lightcurable MTA-like material for pulp capping. Gandolfi, M.G., Siboni, F. and Prati, C. 2012, Int. Endod. J., Vol. 45, pp. 571-9.

55. Cytotoxic effects of resin components on cultured mammalian fibroblasts. Hanks CT, Strawn SE, Wataha JC, and Craig RG. 1991, J Dent Res, Vol. 70, pp. 1450-5. 
56. Biocompatibility of resin-based dental materials applied as liners in deep cavities prepared in human teeth. de Souza Costa CA, Teixeira HM, Nascimento AB, Hebling J. 2007 , J Biomed Mater Res B Appl Biomater, Vol. 81, pp. 175-84.

57. Human pulp response to resin cements used to bond inlay restorations. de Souza Costa CA, Hebling J, Randall RC. 2006, j Dent Mater, Vol. 22, pp. 954-62.

58. Evaluation of temperature changes in the pulp chamber during polymerization of light-cured pulp-capping materials by using a VALO LED light curing unit at different curing distances. Savas, S., et al. 2014, J. Dent. Mater, Vol. 33, pp. 764-9.

59. Analysis of organic components in resin-modified pulp capping materials: Critical considerations. Nilsen, B.W., et al. 2017, Eur. J. Oral Sci., Vol. 125, pp. 183-94.

60. The reparative capacity of different bioactive dental materials for direct pulp capping. Kamal, E., et al. 2018, Dent. Med. Probl., Vol. 55, pp. 147-52.

61. Calcium hydroxide in the treatment of pulpless teeth with associated pathology. GS., Heithersay. 1975, J Br Endod Soc; Vol. 8, pp. 74-93.

62. The effect of composition on the erosion properties of calcium hydroxide cements. Prosser HJ., Groffman DM., Wilson AD. 1982, J Dent Res, Vol. 61, pp. 1431-35.
63. In vitro cytotoxicity evaluation of different pulp capping materials: a comparative study. Poggio C., Ceci M., Dagna A., Beltrami R., Colombo M., Chiesa M. 2015, Arh Hig Rada Toksikol, Vol. 66, pp. 181-8.

64. Flow Line, Durafill VS, and Dycal toxicity to dental pulp cells: effects of growth factors. Furey A., Hjelmhaug J., Lobner D. 2010, J Endod , Vol. 36, pp. 1149-53. .

65. Cytotoxicity and biocompatibility of resin-free and resinmodified direct pulp capping materials: A state-of-theart review. B., CHEN L. and In SUH. 1, 2017, Dental Materials Journal, Vol. 36, pp. 1-7 .

66. Effects of unpolymerized resin components on the function of accessory cells derived from the rat incisor pulp. Jontell M, Hanks C.T., Bratell J, Bergenholtz G. 1995, J Dent Res, Vol. 74, pp. 1162-7.

67. Evaluation of cytotoxicity of VLC Dycal in tissue culture for clinical use. . Kaga M, Seale NS, Oikawa K. 1989, Shoni Shikagaku Zasshi, Vol. 27, pp. 313-6.

68. Cytotoxicity comparison of three current direct pulpcapping agents with a new bioceramic root repair putty. $\mathrm{J}$ Endod 2012; 38: 385-388. Hirschman WR., Wheater MA., Bringas J.S, Hoen MM. 2012, J Endod , Vol. 38, pp. 385-8.

69. Poggio C., Arciola CR., Beltrami R., Monaco A., Dagna A., Lombardini M. et al. Cytocompatibility and antibacterial properties of capping materials. Scient World J . 2014. 